\title{
Social Consequences of Nomadic Working: A Case Study in an Organization
}

\author{
Ramanjit Singh and Trevor Wood-Harper \\ Manchester Business School, \\ University of Manchester, \\ Oxford Road, \\ Manchester M13 9PL, United Kingdom
}

\begin{abstract}
This research study identified social challenges that knowledge workers in the Swedish organization TeliaSonera (Telia) face when utilizing wireless technologies to conduct work on the move. Upon collecting the relevant research data, five problem areas were identified: work and life balance, addiction, organizational involvement, nomadic work and control, and individual productivity. Each problem area was examined with the philosophical underpinning of socio-technical design principles. The results confirm that better role boundary management, self-discipline, work negotiation, and e-mail communication skills may be required for the knowledge workers to manage the demands of nomadic working. Similarly, rewarding nomadic work performance, building employeesupervisor trust relations, and designing jobs that enhance work and life balance can be imperative.
\end{abstract}

Keywords: Nomadic work, wireless technology, socio-technical, work-life balance, career development, productivity.

\section{Introduction}

There is a major restructuring going on in various industries. Organizations are moving away from traditional hierarchies to networks and from centralization to decen-tralization in that parts of the organization are operated as semi-autonomous work units (Malone 2004). These structural changes are not necessarily new. When Ken Olsen founded the Digital Equipment Corporation in 1957, his initial business was based on a decentralized network structure, each unit being responsible for its own production, supervision, and profits. As business grew, this was changed to a more hierarchical structure. The network structure was believed to be destructive as it resulted in replication of resources and intense competition between various business units. In Mumford's (2006) view, companies may face problems in applying these new organizational structures since they may not understand them well. For example, who ought to make major decisions in these companies and how is performance measured? It is believed that complexity can be lessened by discretion, cooperation, and knowledge sharing. Although there are few examples of the network approach in the world, Scandinavian companies have been most successful in combining efficiency with equality. Nevertheless, opponents of this approach suggest that 
managing complexity requires flexibility and a loose organizational formation, whereas profit maximization requires command and control management. These two strands of thinking may have difficulty coming together. Also, democratic work methods may receive little attention when capitalism first and foremost requires wealth for the shareholders.

The nature of work has been changing for a long time and in the last decade there has been a shift from manufacturing to service jobs. There has also been an increase in highly skilled knowledge jobs. Knowledge work can be defined as intellectual work performed to generate valuable information and knowledge. Since an important part of knowledge work consists of nomadic computing, the positive and negative impacts on productivity are subject to the work processes of knowledge workers (Davis 2002). When compared to traditional ways of working, nomadic work provides greater flexibility while freeing the knowledge worker from time and place constraints. Knowledge work is an important part of many organizations today, hence the efficiency of knowledge workers is an important concern (Grudin 2002). Because of the need to excel, knowledge workers require greater freedom, autonomy, and diversity in their work. Hence, decentralized network structures are adopted so that individuals may work in groups and have greater responsibility over their tasks. These recent changes in organizational structure may encourage the adoption of nomadic working. There are many reasons for organizations to test this type of work formation, particularly given the rapid increase in affordable wireless technologies.

Although nomadic work arrangements enable firms to reduce costs while increasing work flexibility, there are numerous challenges and threats faced by knowledge workers (Sorensen 2004). Thus, this research study will identify social challenges that knowledge workers in the Swedish organization TeliaSonera (Telia) face when utilizing wireless technologies to conduct work on the move. More specifically, knowledge workers' management, computing, communication practices with respect to the use of laptops, pocket PCs, PDAs, and/or cell phones in nomadic working will be investigated.

\section{Literature Review}

The major departure point of this research study was the observation that within the literature on mobility, research on the use of wireless technologies in organizations was underrepresented. Aside from a small number of research initiatives that consider the social impact of wireless technology in organizations, much of the literature has been on conceptualizing mobility. There has been a focus on studying the mobile interaction of mobile workers and thereby creating models of mobility (i.e., spatial, temporal, contextual). These models have been used to understand how mobile workers define various categories of context such as work and home given the use of wireless technology in spatial mobile work. There also have been attempts to examine how mobile workers dynamically reconfigure their workspace and move between various work locations. In an attempt to gain an understanding of the potential impact of novel technological developments on organizational communication and cooperation, numerous studies on the use of the mobile phone have been 
conducted. But here too, the aim of these studies has been to develop a conceptual discussion of mobile work practices (Elaluf-Calderwood et al. 2005).

Although the existing literature highlights advantages of increased mobility, there is little evidence that identifies the problems that individuals face while utilizing wireless technologies in the workplace. The importance of identifying social consequences of nomadic working has been echoed by many scholars given the diminishing boundaries between work and social life. It was also found that nomadic working may reduce visibility in the organization, which in turn may lower career advancement prospects (Davis 2002; Jarvenpaa et al. 2005; Lamond et al. 2003). Finally, the inability to use wireless devices securely can slow down the adoption process (Lyytinen et al. 2004). All of these claims provide a need to study how wireless technologies are used in organizations and what are the inherent social consequences involved in nomadic working. Especially pertaining to the literary context, it is important to investigate whether nomadic working reduces work-life balance, involvement in the organization, and individual productivity, and whether nomadic working increases management control and adds to the cost of information. The conceptual framework will be discussed next.

\section{Conceptual Framework}

The nature of work has been changing for a long time and in the last decade there has been a shift from manufacturing to service jobs. There has also been an increase in highly skilled knowledge jobs. Knowledge work is an important part of many organizations today, hence the efficiency of knowledge workers is an important concern (Grudin 2002). Because of the need to excel, knowledge workers require greater freedom, autonomy, and diversity in their work. Hence, decentralized network structures are adopted so that individuals may work in groups and have greater responsibility over their tasks. These recent changes in organizational structure may encourage the adoption of nomadic working. There are many reasons for organizations to test this type of work formation, particularly given the rapid increase in affordable wireless technologies.

For organizations, the benefits of nomadic working are lower overhead costs such as office space and supplies, while individuals benefit from more flexible working hours; more time for managing home and family life; reduced need for commuting; greater autonomy over work processes; fewer interruptions while working; and the chance to remain at work even if becoming sick or taking child-care leave. Most of these direct benefits have an indirect impact on the job and life satisfaction, including physical health. The set of benefits for society as a whole includes heightened community stability; improved entrepreneurial effort; less environmental pollution; and more effective use of energy sources. Although there may be many perceived benefits, possible negative consequences of nomadic working include poor career advancement opportunities, increased conflict between work and family life, and social isolation. Negative organizational consequences may include purchase of suitable equipment, training and support overhead, along with health and safety provisions (Lamond et al. 2003). 
It is believed that there will be a significant increase in nomadic working in the future (Sorensen 2004). Although the idea is not new, advances in information and communication technologies are enabling workers to access organizational data, collaborate with colleagues, and remain in touch with customers and suppliers, working effectively anytime anywhere (Lyytinen and Yoo 2002). The success of nomadic working requires that both employer and employee have mutual trust. In addition, it is important that the employer provides the employee with acceptable rewards, job satisfaction, and job security. Creating a nomadic culture in an organization will not be an easy task, but failure to do so will lead to alienation and a dissatisfied workforce (Mumford 2006). Although Fok et al. (1987) provided important guidelines for designing socio-technical jobs in the past, their use may no longer be fruitful in designing the work systems of today. Hence, Singh et al. (2008) propose the use of socio-technical principles for designing jobs for the decentralized organization of the $21^{\text {st }}$ century.

- Assumptions about the organization:

- It is an open system, which interacts with the environment

- It is composed of two autonomous yet interrelated subsystems: social and technical

- Assumptions about employees:

- From Theory Y's point of view, it is ethical to let people participate in the decision-making process

- $\quad$ Socio-technical work design aims:

- Joint satisfaction of technical (work efficiency) and social(work-life) goals of the organization

- Assumptions about the socio-technical work design process:

- Worker participation is essential

- $\quad$ Socio-technical work design concepts:

- Work system, not single job, as design unit

- Workgroup not single jobholder

- Internal regulation of group

- Redundancy of function, not redundancy of parts

- Members have discretion, not highly prescribed work

- Develop flexible learning system

- Autonomous workgroup is superior form of organization

- Role changes:

- Designer: facilitator not expert

- Worker: designer of the system

- Manager: boundary manager, not supervisor of workers

\section{Research Method}

Since the purpose of this study is to identify social consequences of wireless technology for nomadic working, socio-technical theory provides a powerful tool for analyzing the research findings. The socio-technical view sees organizational workers as social actors who interact with technological artifacts and institutional forces to construct a meaningful reality in the workplace (Lamb and King 2003). In 
addition, the socio-technical theory views ICT as a social phenomenon enmeshed within institutional structures (Orlikowski and Iacono 2001). The enmeshed nature of ICT implies that it may be difficult to classify best practices and use them in another context. Hence, since people and technology in organizations are both social entities, their countless interactions demand stronger conceptualizations. Socio-technical theory provides this feature for such interpretive analysis (Lamb 2005). Because socio-technical theory is concerned with social phenomena, it is also commensurate with interpretive epistemology.

There are many ways to investigate the social consequences the employees face while using wireless technologies for nomadic work. In order to research this area of interest, the decision was made to perform a case study at Telia. Case study research provides an in-depth analysis of complex social phenomena in its natural setting, asking why certain events occurred in the situation (Oates 2006). There are many data collection techniques that can be used to conduct a case study. Data gathered from multiple sources can provide researchers with rich and detailed facts. For the purpose of this research, structured interviews and documents were utilized for data collection. According to Benbasat et al. (1987), case study research may be important for understanding individuals' experiences and viewpoints, as well as the action context. Hence, the case study approach will be very useful for identifying the social consequences that knowledge workers face while utilizing wireless technologies for nomadic working.

\section{Case Study at Teliasonera}

TeliaSonera is the leading telecommunication organization and mobile network operator in the Nordic region and it has also a strong hold on the mobile communication market in Eurasia. In Sweden, TeliaSonera is known as Telia. Telia offers a broad range of telecommunication services to residential and business customers. The residential customers are served by Telia stores and other independent retailers in the country. In addition to the retail stores, Telia has management offices for its four divisions in major cities and towns in Sweden (TeliaSonera 2007c). In order to facilitate out-of-office work, all management employees are provided with a wireless laptop and a cell phone. By using the wireless laptop, employees can access the company intranet as well as the Internet (Telia 2007). The primary purpose of Telia's intranet is to increase workforce productivity by enabling employees to instantly locate and view information and applications appropriate to their roles and responsibilities. By the use of a web page, employees can retrieve the data held in any database anytime anywhere, increasing their ability to carry out jobs faster and with confidence that they have the correct information. Once updated, the information is easily published and stored for others to see and use (Kuu and Lundberg 2007).

Employee health and safety is very important to Telia (TeliaSonera 2007b). This involves not only safe working conditions but also psychological well-being and social welfare. Thus, Telia recognizes the need for a balance between work and life, and the organization offers flexible working hours and provides for telework (TeliaSonera 2007a). Hence, employees can work at home, while traveling, or from a telecenter, while rights and duties remain the same as in the fixed workplace (office). 
Telework is a voluntary work option and it can be changed at any time; financial rewards are based on work performance rather than employee visibility in the organization. Before the employee can start working, he/she needs to agree with their supervisor on the hours that they can spend working out-of-office.

For the purpose of data collection at Telia, two trips to Sweden were made between November 2007 and January 2008. During the first trip, seven interviews were conducted with knowledge workers (management employees) from the Broadband Services and Mobility and the Integrated Enterprise Service divisions in Stockholm. The participants selected performed a significant amount of their work out-of-office using wireless technologies such as laptop and cell phone. During the second trip, 12 additional interviews were conducted with Telia's knowledge workers in Stockholm and Gavle. Although there was an attempt to conduct additional interviews, it was not possible due to Telia workers unwillingness to provide information on company's work methods and technologies. Also, many individuals were reluctant to reveal the impact of work-life imbalance on their mental and physical health. Upon collecting and transcribing the data from interviews and documents, a case study on Telia's knowledge workers' nomadic work practice was developed and five themes were identified. The five research themes are work and life balance, addiction, organizational involvement, nomadic work and control, and individual productivity.

\subsection{Work and Life Balance}

A flexible work hour scheme requires individuals to work from home, leaving little time for social activities with family and friends. When asked if work during the evenings and weekends is reducing social time with family and friends, one employee said: "It happens; I work both during evenings and weekends. I read and reply to $e$ mails on Sundays because I do not get the time to read all the mails during weekdays. This happens when I have many meetings in the office. All meetings generate action points and these actions points often require immediate attention." Another employee commented: "I may work during weekends if I need to meet a deadline or resolve a customer complaint. For instance, we sent incorrect electronic invoices to customers once; this fault required that we had to work during the weekend to correct the invoices so that we could resend them on Monday." Work from home leads also to social isolation as there is room for face-to-face interaction with work colleagues. One employee's remark on the matter is worth repeating: "Yes, I was working in the Telia's retail store last year and I was spending eight to nine hours each day at work. Even though I was physically tired at the end of the week, I was able to find time for my family and friends during weekends. But now, since I have limited interaction with people at work, I am sometimes feeling isolated and depressed. Due to the depression, I do not meet-up with my friends during weekends. Also, I do not enjoy the company of my family because I am concerned if I will be able to complete the assigned work on my own and within the allocated time."

\subsection{Addiction}

Individuals have developed an urge to log onto their laptop or cell phone and engage in work related e-mail communication during evenings and weekends. When asked, 
one employee said: "A major part of my work consists of e-mail communication. So, I do read e-mails as they come in my Inbox. I need to also write reports in my work, but due to the excessive e-mail communication, I am sometimes unable to complete work on-time. I believe this is due to lack of discipline. I should not be engaging in $e$-mail conversations when I am writing reports. But due to the strong urge to read emails, I am sometimes overusing the technology." Another employee expressed similar concerns, saying: "I am working during evenings but I try not to work during the weekends. I switch off my cell phone and I never log onto my laptop during weekends. You need to have self-control and not overuse the technology to get this balance between work and social life. For instance, last week, I was browsing the Internet and before knowing it, I had spent 4 hours on the Internet. That is really scary to me, that's why I try not to log onto the laptop during weekends. I think it is very important for us to go out in the fresh air and meet other people."

\subsection{Organizational Involvement}

Nomadic working leads to low information awareness for making sense of what is going on in the organization. When asked, one employee said: "My entire work group is geographically dispersed in Sweden so I meet them once every month. I would like to meet them more because you can never know on the phone how the other person is feeling. So, this distant work relationship may impede the socialization process and the formation of social bonds among group members." Low visibility in the organization also deteriorates interpersonal relations with key officials in the organization, which in turn may reduce promotion prospects. When asked, one employee summed the viewpoint of many: "It is important that you have a regular face-to-face contact with your supervisor. By having a regular contact with your supervisor, you can better market yourself and 'demand' promotion when the opportunity emerges. If you are working too much from home or are based at a different city than your supervisor, then you may not receive the work guidance that you need for producing good results." In addition, employees based in small-town offices feel that they are at a disadvantage since they do not have the opportunity to visit the head office in Stockholm regularly. When asked, one employee said: "It is important that you are based in the same office as your supervisor. For instance, since most of the supervisors are based at the Stockholm office, it is important for your career that you work at the Stockholm office. I believe that individuals that are based at small cities such as Gavle or Lulea may have lower advancements opportunities because they do not have regular face-to-face contact with their supervisor."

\subsection{Nomadic Work and Control}

Nomadic working is not fully trusted as the organization requires its employees to be where they can be seen. Lack of trust can lead to severe consequences for the firm. If workers believe they are not trusted, they will engage in bureaucratic activities to show their work-efficiency and protect themselves against a system they do not trust. When asked why Telia requires its employees to spend more time in the office, one employee reported: "For the past two or three years, management has been tightly 
regulating nomadic work arrangements since there have been disciplinary problems in a few work groups. So supervisors nowadays advise people to come to the office on daily basis. But, on the other hand, Telia's nomadic working policy encourages you to work where you feel most productive and convenient. So, it is a contradiction from management's side. This controlling behavior may be having a negative impact on mutual trust relations between the workers and the management."

\subsection{Individual Productivity}

Communication at Telia is primarily via cell phone and e-mail. Although cell phone communication is not disturbing, the sheer volume of e-mail communication can be overwhelming. One senior management employee summed up the viewpoint of many: "I believe that people are sending a lot of e-mails in the organization. I receive between 70 and 80 e-mails per day. There are e-mails where I am the main recipient and there are e-mails where I am the copy recipient. I read e-mails where I am the main recipient but I do not read e-mails where I am the copy recipient. I do not have time for reading copy recipient e-mails. I forward these e-mails to a folder which I never read. So, I ask myself, what is the benefit of sending so many copies of e-mails? Why do people send them? I think we have a sickness about informing everyone in the organization and this is why we send so many e-mail copies. We need to be more serious about sending e-mail copies to each other. Information should be sent to those that really need it and not to everyone." Although e-mail communication is an important part of work at Telia, it may reduce productivity. When asked about the impact on productivity, one employee said: "The e-mail communication can be time consuming; it takes time to sort and read through all the relevant e-mails. If I reply to all e-mails, I will have less time to finish work. So, yes it is stressful to receive so many e-mails and I believe it is having a negative impact on my productivity." Another employee expressed similar concerns: "A major part of my work consists of e-mail communication. So, I do read the e-mails as they come to my in-box. I also need to write reports in my work, but due to the excessive e-mail communication, I am sometimes unable to complete work on time. I believe this is due to the lack of self-discipline. I should not be engaging in e-mail conversations when I am writing a report."

\section{Result Discussion}

\subsection{Work and Life Imbalance}

Socio-technical theory has been based on the assumption that organizations are physical entities and their members are all physically present in one place. This, however, is not the case nowadays as organizations are loosely structured and workers have the freedom to work out-of-office using wireless technologies. Given this decentralized nature of work, some of the basic design principles are false. The increasing utilization of wireless technologies and electronic-mediated communication increases the means by which individuals can cross work and life boundaries. The increasing need to be responsive to organizational demands has made boundary crossing a requirement of nomadic working. Utilizing ICT for enabling anytime 
anywhere work may increase the productivity of individuals or it may disrupt either sphere (i.e., work and social life). Boundary crossing in this way may become problematic for organizations, especially when conventional management techniques are used to manage work (e.g., command and control rather than coordinate and cultivate). The emphasis on traditional management approaches can significantly reduce trust building in an organization. Moreover, there is a risk that boundary crossing may damage interpersonal relations with family and friends. As there is everywhere to go but nowhere to hide from work demands, little time may be available for engaging in social activities.

On the organizational level, it is important that companies design jobs that enhance the work and family balance. Although many organizations have restructured their work to meet $21^{\text {st }}$ century demands (e.g., adding telework and leave policies), they have not changed their organizational culture and values because this is much more difficult to achieve. According to the socio-technical view, a more flexible organization should be aligned with workers' homes in terms of purpose and culture. Not surprisingly, many companies have developed telework programs to serve their own purpose with disregard to employees and their families, which eventually results in unrealized expectations and cynicism. In addition, if it is not feasible or desirable for an organization to alter its culture, then work and family systems must be kept separate so that workers can attain balance. A call has been made by researchers to rethink cultures in order to accommodate families, but these propositions have yet to be considered seriously by most organizations. The socio-technical theory suggests balance by increasing support structures that facilitate communication between organizational members (supervisors and employees). In addition, most supervisors are given discretion to bend rules. They need to use this authority to accommodate individuals' family situations. Supervisors are very important to employees' ability to attain balance, and a handful of organizations have required supervisors to undertake training in handling situations that require support for employees' family situations. Consistent with the research findings, a final suggestion for increasing work and life balance is employee empowerment. For instance, employees who have the authority to take leave for handling their family responsibilities will undoubtedly improve the work and family balance. Similarly, the ability to say no to additional work assignments can improve the balance.

Furthermore, improved communication may be required for achieving a better balance between work and social life; for example, by regularly talking about what individuals have been doing at various times - sharing some of the stories about challenges and successes at work with family, or telling colleagues and supervisors about family events and social happenings. Individuals can also inform others of their unavailability in either system through ICT-enabled context switches (e.g., using voice mail or auto-reply e-mail). Understanding and support are more likely to come from colleagues, supervisors, family members, or friends if they are aware of othersystem events and happenings. Trust will also be reinforced if others are informed of individuals' unavailability in either system. Employees can also increase their involvement at both work and home by developing strong interpersonal relations at work and home, becoming proficient at work as well as in household tasks, and making both work and home more important parts of self-identity. Increased 
involvement in both systems can result in increased influence over others, thereby creating better prospects for an improved work and life balance.

\subsection{Compulsive Work Behavior}

Addiction to information is another growing problem among Telia employees. Since individuals can easily access information on the intranet as well as the Internet, they may have developed an urge to engage in work-related activities, e-mail communication, or social media (e.g., Facebook, blogging, podcasts, etc.) using wireless technologies. In fact technology has become a part of knowledge workers and that they experience high levels of anxiety when set apart from their wireless devices. They have continual thoughts about their involvement with technology, and their hobbies are technology related. They are frequent users of the Internet, which often intrudes on their social life, and on vacation they bring along their laptop, pocket PC, PDA, and/or cell phone, even though they do not need to do any work.

Research on workaholism reports that technology increasingly facilitates addiction to information, which in turn gives rise to workaholic behavior. Individuals that show workaholic behavior spend a lot of time in work activities, even if it means giving up important family or recreational activities. Workaholics are also psychologically attached to their work even at times whey they are not working, while their work performance almost always exceeds the expectations of people working around them. Although it may be difficult to control the behavior of workaholism, increasing work demands provide a condition in which workaholic behaviors thrive. If workaholism is encouraged in an organization, it may give rise to a culture that requires adaptation of all employees to the workaholic behavior. Porter and Kakabadse (2006, p. 548) define this adaptation "as a process in which the person is adapting to that very behavior that for some becomes the addiction." An important factor that provides additional support to the organization's rising demands and the employee's inner desire to stay connected to work is the rise of wireless technology as it enables people to stay connected to the organization around the clock. Although not all people become addicted to a given substance, there is a possibility that some people may over-adapt and start to direct all their attention to the addiction by giving up other satisfactions in life. Just as some smokers and drinkers cannot quit even when their physical health badly deteriorates or their family and friends find life with them difficult, the same is true for people who show a constant need to be involved with their computer and work.

There are health consequences in both cases, as well as interpersonal problems with family members and friends. According to the socio-technical view, when new technologies are adopted, there are unintended consequences for the workers involved. The necessary focus on the implementation of the technology overshadows the social and personal needs of the users. The ever-increasing nomadic work environment, hence, leads not only to new commercial opportunities, but also to new social challenges (i.e., addiction to handheld devices and workaholism). It would seem that the recent technological advances and decentralized organizational structure offer an opportunity to realize the fit between human needs and managerial performance that Mumford strove to promote through her own research work. Nevertheless, the most complex barrier to break through may be the ethical one, as we 
continually aim to reconcile the values and viewpoints of employers with those of employees in the face of ever-increasing global competition fueled by a ubiquitous ability to access and manipulate information.

\subsection{Lower Career Development}

Telia's telework policy allows employees to work from where they feel most comfortable and effective. Employees can work from home, while travelling or from a remote location using wireless technologies, and their presence in the office has little significance as rewards are based on performance. However, interviews with Telia's management employees revealed that visibility in the office and regular faceto-face contact with supervisors has an important impact on career development. An organization serious about promoting nomadic work must base its rewards on employee work performance rather than on work location. It is also recommended that reward structures must be based on efficiency gains through alternative work methods (i.e., nomadic work). Ensuring workers that pay is comparable to that of workers in different locations is also important in cultivating decentralized work methods. Yet, Telia still values and rewards in-office work and takes for granted that time spent in the office equals higher commitment and productivity. Thus, for nomadic working to be successful, the culture in the organization must be one of trust. A culture that is based on the principles of trust requires reconsideration of what it means to be working and how the organization values and rewards performance. An organization serious about promoting a nomadic work culture must reward its employees based on their performance rather than on time spent in the office.

At the organizational level, a telework policy is necessary for establishing formal communication between the employees and supervisors. Although Telia has a telework policy that employees and supervisors can follow to establish formal nomadic working agreements, including the ways of communicating, this policy is not widely communicated and used in the organization. As nomadic working is a new phenomenon, there are still many issues that need to be resolved and communicated to employees through a formal telework policy. While formal communication is necessary for informing workers about work-related issues, informal communication is also necessary for developing social relations and for fostering community spirit in the organization. Hence, supervisors need to develop relationships with employees who may not be in the same place. A critical factor for the success of nomadic working, communication must be bilateral, flowing not only from supervisors to employees but also from employees to supervisors and colleagues. Communication is particularly important at the employee level. As this study has shown, without the social interaction of a conventional workplace, employees are more likely to feel social isolation. Lack of emotion and non-immediate response over the phone or Web can make communication superficial and formal. The socio-technical design principles suggest effective organizations must provide opportunities for team members to meet face-to-face so that they can know each other on a personal level for facilitating open exchanges of ideas and knowledge sharing in the organization. This can be attained through face-to-face team-building exercises, which combine workshops with fun social events such as go-carting or bowling. 


\subsection{Heightened Management Control}

Although Telia's telework policy allows its employees to work anytime anywhere, many supervisors want the employees to come to the office on a regular basis. An organization that requires its employees to be where they can be seen may be going against the fundamental values and beliefs of nomadic working, and this behavior will undoubtedly cause the trust relations in the company to deteriorate. Lack of trust can lead to severe consequences for the firm. If workers believe they are not trusted, they will engage in bureaucratic activities to show their work efficiency and protect themselves against a system they do not trust. Sadly, there are no short cuts for cultivating mutual trust relations in the company. It is important that both workers and supervisors apply appropriate ethics and reward systems when designing telework programs. This can happen if the workers are allowed to create and share knowledge in a self-regulating group. Likewise, supervisors must lessen the control and enable the group members to handle the issue of trust internally. The duty of top management may be to nurture supportive behaviors, encourage open communication, and arrange social events in the organization. Technology-mediated communication does not express the same level of emotional response that face-to-face communication provides; thus group members may be unaware of contextual and situational cues that stimulate other team members; what is normal behavior to some may be disturbing to others. When group members are only available virtually, it is more difficult to develop the social bonds that may result in trust based on judgment.

Therefore, the challenge for supervisors is to develop trust in teams and cultivate trust throughout the team's life. This challenge is overwhelming because evidence shows that trust develops at different phases in a team's lifecycle. Also, it was found that training and reward systems have a significant impact on the development of trust in teams. First, it is important to ensure that selected team members can fulfil their respective functional roles; if the potential members do not possess the skills, training must be provided so that they can carry out the project tasks successfully. Training on "being virtual" is also critical at this phase, as team members may come from different technical and cultural backgrounds and, therefore, may be unaware of the importance of careful composition and expression of ideas and opinions. Lags in email responses can also be misinterpreted as a lack of commitment or lack of functional ability, something which may result in faster dissolution of trust than would be otherwise expected.

Training can help the organization to become aware of these issues and thereby educate its employees in how to avoid them. An organization serious about developing trust in virtual teams must provide training to both employees and supervisors, with an emphasis on trust and working to agreed objectives and work outcomes. Team members need to demonstrate their integrity by not abusing the freedom they have in the nomadic work environment. Supervisors (with the support of the organization) need to determine whether employees are employed to generate outcomes or to perform activities in the office. They need to believe that employees will carry out their duties and behave even though they are not being watched; that they will have self-initiative and self-discipline. 


\subsection{Information Overload}

Even though ubiquitous access to information and people may have a positive impact on productivity, it was found that many employees at Telia reported lower productivity, due to the sheer volume of unstructured and irrelevant e-mail communication that takes place in the organization. While unstructured e-mail communication may be due to self-negligence and lack of e-mail composition skills, the irrelevant e-mail communication may be due to the distribution of e-mails copied to multiple recipients. While e-mail is an important part of everyday work communication, the sheer volume generated is an increasing problem. Everyone in the organization is facing information overload, but is unable to do anything about it since information may be coming from several communication sources.

While it is important to build a network of information exchanges in the organization, it must not lead to information overload, and to reduce it individuals should have the autonomy to determine the amount of communication in which they engage (Singh et al. 2008). One way knowledge workers can reduce the likelihood of information overload is by turning off the e-mail alert and sound. Then, limiting the use of the "e-mail-to-all" and "reply-to-all" button is important for reducing the spread of e-mail; also, using more targeted recipient groups may be useful. Configuring the inbox to display only sender, subject area, and the initial three lines of the content is an important consideration as it will enable the recipient to quickly determine if the message is urgent and requires an urgent response. Configuring the e-mail software to look for messages no more than every 45 minutes is also essential in training all employees in how to create e-mail priority, perform e-mail maintenance with message rules, create recipient groups and address books, and structure the subject and content of the e-mail. "Outlook" offers several message processing add-ins that can be used to analyze e-mail for errors before sending. The reviewer can suggest changes to the structure or content by adding comments to the message. This tool can be useful for training new employees who may be unaware of corporate e-mail etiquette.

\section{Theoretical Contribution}

Although Singh et al. (2008) provide important guidelines for designing sociotechnical jobs, these guidelines may need to be modified given the social challenges faced by knowledge workers in a nomadic work environment. It is important the workers are given freedom to accommodate their work preferences and life situation. For implementing effective teleworking in the organization, it is important the rewards are based on work performance rather than time spent in the office. The socio-technical work design requires worker participation in the development of various work policies and systems in the organization. Workers need around the clock support for coordinating and communicating on work tasks; they need self-regulation and autonomy to carry out work where they cannot be seen by the management; they need training in a virtual environment; when work is performed by autonomous workgroups, each group member needs ubiquitous access to informational resources. 
The socio-technical principles below depict the necessary steps Telia needs to take for implementing successful nomadic working.

- Assumptions about employees:

- From Theory Y's point of view, it is ethical to let people work where it is most convenient given their life situation and preference

- Socio-technical work design aims:

- Design jobs that enhance the work and family life balance

- Rewards based on employee work performance rather than on work location

- Assumptions about the socio-technical work design process:

- Worker participation is essential

- Socio-technical work design concepts:

- Members have discretion; work can take place anytime anywhere

- Internal regulation of group as well as self discipline

- Availability of shared workspace facilities

- Information awareness support

- Face-to-face team building exercises

- Basic e-mail communication skills

- Autonomous workgroup is superior form of organization

- Role changes:

○ Designer: facilitator not expert

○ Worker: designer of the system

○ Manager: boundary manager, not supervisor of workers

\section{Conclusion}

Knowledge work can be defined as intellectual work performed to generate valuable information and knowledge. Since an important part of knowledge work consists of nomadic computing, the positive and negative impacts on productivity are subject to the work processes of knowledge workers. When compared to traditional ways of working, nomadic work provides greater flexibility while freeing the knowledge worker from time and place constraints. Even though nomadic work may increase knowledge workers' productivity, it may also have unintended and undesirable consequences. Thus, the identification of social consequences of nomadic working with respect to the use of wireless technologies such as laptops, pockets PCs, PDAs, and cell phones was investigated in this research. Management workers at the Telia organization in Sweden were approached for the purpose of carrying out the research study. Upon collecting the relevant research data, five problem areas (themes) were identified: work and life balance, addiction, organizational involvement, nomadic work and control, and individual productivity. Each theme was discussed with the philosophical underpinning of socio-technical theory. On the individual level, the findings confirm that better role boundary management, self-discipline, work negotiation, and e-mail communication skills may be required for knowledge workers to manage the demands of nomadic working. On the organizational level, rewarding nomadic work performance, building employee-supervisor trust relations, and designing jobs that enhance work and life balance can be fruitful. 


\section{References}

Benbasat, I., Goldstein, D.K., Mead, M.: The Case Research Strategy in Studies of Information Systems. MIS Quarterly 11(3), 369-386 (1987)

Davis, G.B.: Anytime/Anyplace Computing and the Future of Knowledge Work. Communications of the ACM 45(12), 67-73 (2002)

Elaluf-Calderwood, S., Kietzmann, J., Scaccol, A.Z.: Methodological Approach for Mobile Studies: Empirical Research Considerations. London School of Economics, London (2005)

Fok, L.M., Kumar, K., Wood-Harper, A.T.: Methodologies for Socio-Technical Systems (STS) Development: A Comparative Review. In: DeGross, J.I., Kriebel, C.H. (eds.) Proceedings of the Eighth International Conference on Information Systems, Pittsburgh, PA, pp. 319 334 (1987)

Grudin, J.: Group Dynamics and Ubiquitous Computing. Communications of the ACM 45(12), 74-78 (2002)

Jarvenpaa, S.L., Lang, K.R., Tuunainen, V.K.: Friend or Foe? The Ambivalent Relationship between Mobile Technology and its Users. In: Sørensen, C., Yoo, Y., Lyytinen, K., DeGross, J.I. (eds.) Designing Ubiquitous Information Environments: Socio-Technical Issues and Challenges, pp. 29-42. Springer, Boston (2005)

Kuu, T., Lundberg, A.: A Role-Based Intranet: Overcoming Information Overload?, Vaxjo University, Sweden (2007) (unpublished paper)

Lamb, R.: On Extending Social Informatics from a Rich Legacy of Networks and Conceptual Resources. Information Technology \& People 18(1), 9-20 (2005)

Lamb, R., Kling, R.: Reconceptualizing Users as Social Actors in Information Systems Research. MIS Quarterly 27(2), 197-235 (2003)

Lamond, D., Daniels, K., Standen, P.: Teleworking and Virtual Organizations: The Human Impact. In: David Holman, T.D.W., Clegg, C.W., Sparrow, P., Howard, A. (eds.) The New Workplace: A Guide to the Human Impact of Modern Working Practices, pp. 197-216. John Wiley \& Sons, Ltd., Chichester (2003)

Lyytinen, K., Yoo, Y.: Issues and Challenges in Ubiquitous Computing. Communications of the ACM 45(12), 62-65 (2002)

Lyytinen, K., Yoo, Y., Varshney, U., Ackerman, M.S., Davis, G.B., Avital, M., Robey, D., Sawyer, S., Sorensøn, C.: Surfing the Next Wave: Design and Implementation Challenges of Ubiquitous Computing Environments. Communications of the Association for Information Systems (13), 697-716 (2004)

Malone, T.W.: The Future of Work: How the New Order of Business Will Shape Your Organization, Your Management Style, and Your Life. Harvard Business School Press, Boston (2004)

Mumford, E.: The Story of Socio-Technical Design: Reflections on its Successes, Failures and Potential. Information Systems Journal (16), 317-342 (2006)

Oates, B.J.: Researching Information Systems and Computing. Sage Publications Ltd., Oxford (2006)

Orlikowski, W.J., Iacono, C.S.: Research Commentary: Desperately Seeking the 'IT' in IT Research-A Call to Theorizing the IT Artifact. Information Systems Research 12(2), 121-143 (2001)

Porter, G., Kakabadse, N.K.: HRM Perspectives on Addiction to Technology and Work. Journal of Management Development 25(6), 535-560 (2006)

Singh, R., Wood-Harper, A.T., Wood, B.: Designing Socio-Technical Systems for the Ubiquitous Information Environments. Scientific Inquiry 9(1), 37-46 (2008) 
Sorensen, C.: The Future Role of Trust in Work-The Key Success Factor for Mobile Productivity: Optimizing the Knowledge Supply-Chain, Microsoft (2004),

http://stuff.carstensorensen.com/Sorensen2004.pdf

Telia. About Telia HomeRun (2007),

http: / /www.homerun.telia.com/eng/about/ (accessed November 28, 2007)

TeliaSonera. CSR: Flexible Working (2007a), http://www.teliasonera.com/about_teliasonera/csr/workplace/ flexible_working (accessed November 28, 2007)

TeliaSonera. CSR: Health and Well-Being (2007b), http://www.teliasonera.com/about_teliasonera/csr/workplace/ health_and_wellbeing (accessed November 28, 2007)

TeliaSonera. Markets and Brands: Sweden (2007c), http: / /www.teliasonera.com/about_teliasonera/ markets_and_brands / sweden (accessed November 28, 2007)

\section{About the Authors}

Ramanjit Singh recently completed his Ph.D. the at Manchester Business School, University of Manchester. In addition to his doctoral research, he has published a paper in Scientific Inquiry, a report at the University of Trento, Italy, and five conference papers. He can be reached by e-mail at raman.si@gmail.com.

Trevor Wood-Harper is a professor of Information Systems at the Manchester Business School, University of Manchester. He has authored, coauthored, or coedited 20 books and proceedings, and has published over 200 research articles. He has supervised or co-supervised more than $30 \mathrm{Ph}$.D. students. He can be reached by email at atwh@mbs.ac.uk. 